\title{
Navy Real-time Global Modeling Systems
}

Robert C. Rhodes, Harley E. Hurlburt, Alan J. Wallcraft, Charlie N. Barron, Paul J. Martin, E. Joseph Metzger, Jay F. Shriver, Dong S. Ko Naval Research Laboratory. Stennis Space Center, Mississippi USA

\section{Ole Martin Smedstad}

Planning Systems, Inc. . Stennis Space Center, Mississippi USA

\section{Scott L. Cross}

Naval Oceanographic Office. Stennis Space Center, Mississippi USA

\author{
A. Birol Kara \\ Florida State University. Tallahassee, Florida USA
}

\section{Introduction}

The global ocean has its own "weather" phenomena, although with greatly different time and space scales compared to the atmosphere. Oceanic mesoscale eddies are typically about $100 \mathrm{~km}$ in diameter which makes them 20-30 times smaller than comparable atmospheric highs and lows. The ocean's "jet streams" are the western boundary currents and their extensions into the interior ocean. The currents have speeds on the order of $1 \mathrm{~m} / \mathrm{s}$ compared to atmospheric speeds that can be 100 times this value. The space scales of the meanders on these high-speed streams are similar to those for the eddies mentioned above. Knowing and predicting these oceanic mesoscale features have numerous naval applications which include tactical planning, optimum track ship routing, search and rescue and supplying boundary conditions for high resolution coastal models, to name a few.

However, operational global ocean modeling has lagged far behind atmospheric modeling because the smaller space scales mean approximately four orders of magnitude more computer time and three orders of magnitude more computer memory are required. In addition, unlike the meteorological radiosonde network that provides initial conditions from the surface to the top of the atmosphere, there are very few observations below the ocean surface on a daily basis. Thus, surface satellite observations and an effective method to assimilate these data are a requirement.

In the past few years, computer technology has developed to the point where a system capable of resolving the oceanic mesoscale (i.e. eddy-resolving) can be run on a daily basis. This first generation global ocean prediction capability has been developed at the Naval Research Laboratory (NRL) and all components of the system are running in real-time at the Naval
Oceanographic Office (NAVOCEANO). NRL research dating back to the early 1980s, which focused on high horizontal resolution, satellite altimeter data assimilation, and statistical downward projection of surface satellite observations has led to a system made up of three main components: the Modular Ocean Data Assimilation System (MODAS), the NRL Layered Ocean Model (NLOM), and the NRL Coastal Ocean Model (NCOM). This system provides the Navy with the first global ocean analysis/prediction capability for fleet support and is also a contribution to the operational phase of the multi-national Global Ocean Data Assimilation Experiment (GODAE; International GODAE Steering Team, 2000).

The delivery of the first generation system began in 1999 with a global ocean analysis capability (MODAS), followed in 2000 with the transition of a $1 / 16^{\circ}$ horizontal resolution global ocean model (NLOM) that became the first operational system to properly resolve mesoscale ocean dynamics. It will be completed by the delivery of a $1 /{ }^{\circ}$ global version of the NCOM, with higher vertical resolution in the mixed layer, for improved upperocean prediction and boundary conditions for higher resolution coastal models (Figure 1).

There is strong evidence that ocean models need to use grid cells for each predicted variable that are at most about $7 \mathrm{~km}$ across at mid-latitudes. NRL research has shown that doubling the horizontal resolution to $3.5 \mathrm{~km}$ per cell gives substantial improvement but doubling again to $1.7 \mathrm{~km}$ gives only modest additional improvement (Hurlburt and Hogan, 2000). For the NLOM grid, these resolutions translate to $1 / 16^{\circ}, 1 / 32^{\circ}$ and $1 / 6{ }^{\circ}$, respectively. This is for the global and basin-scale. Much finer resolution is required for coastal regions. At $3.5 \mathrm{~km}$, the optimal resolution is finer than might be 


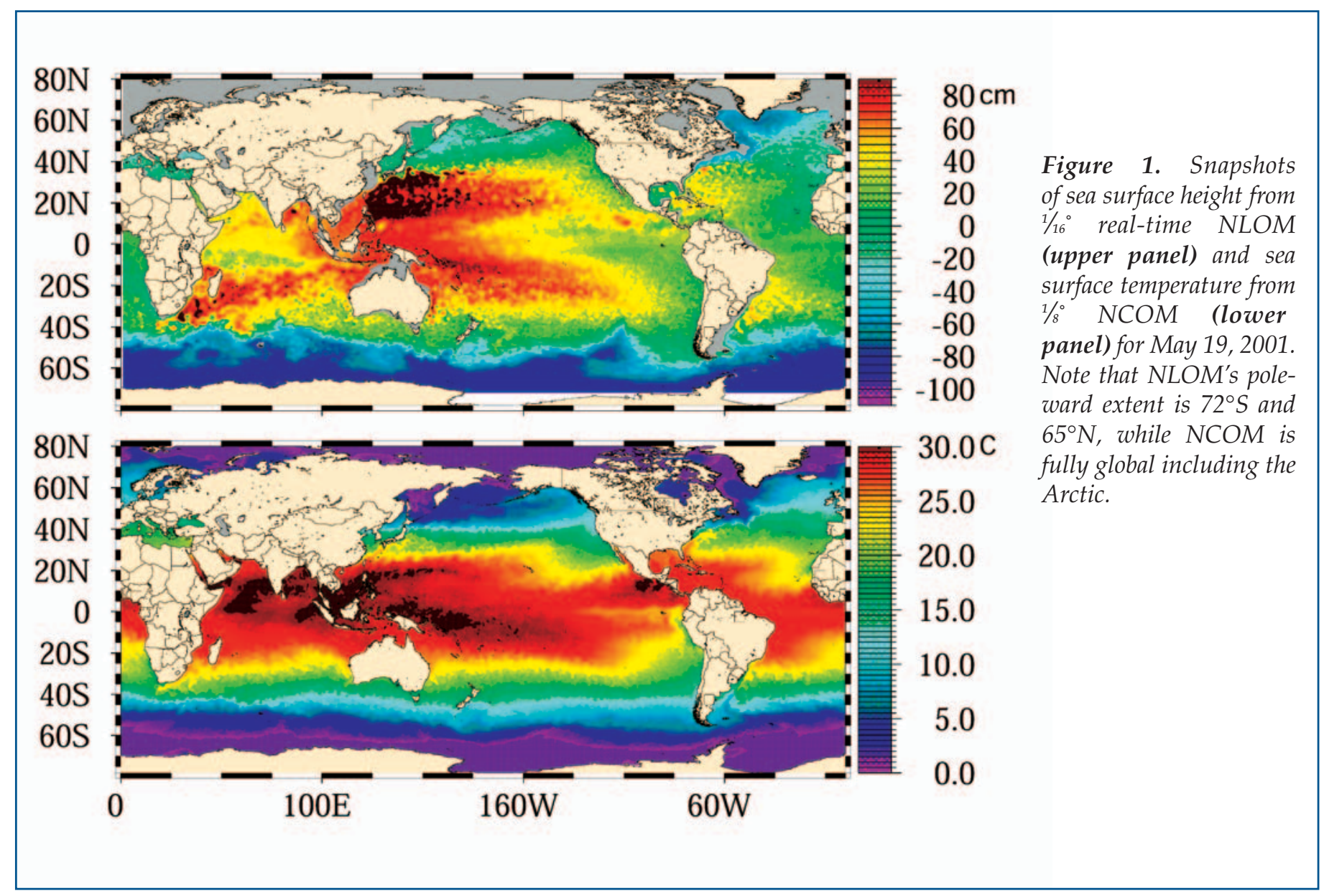

expected based on the size of eddies. In relation to ocean eddy size it is similar to the resolution currently used by the leading weather forecasting models in relation to the size of atmospheric highs and lows.

More specifically, our research has shown that fine resolution of the ocean eddy scale is required to obtain dynamic coupling between upper ocean currents and seafloor topography via flow instabilities, a mechanism that occurs without direct contact between the upper ocean currents and the topography. This coupling can strongly affect the pathways of upper ocean currents and fronts, including the Gulf Stream in the Atlantic, the Kuroshio in the Pacific (Hurlburt et al., 1996; Hurlburt and Metzger, 1998), the East Korea Warm Current in the Japan/East Sea (Hogan and Hurlburt, 2000) and the Tasman Front between Australia and New Zealand (Tilburg et al., 2001). The high-resolution is also required to obtain sharp fronts that span major ocean basins (Hurlburt et al., 1996) and for adequate representation of straits and islands (e.g. Metzger and Hurlburt, 2001). In addition, it can affect the large-scale shape of ocean gyres such as the Sargasso Sea in the Atlantic (Hurlburt and Hogan, 2000). As discussed later, simulation skill for ocean mesoscale features is crucial for an ocean model to act as an effective dynamic interpolator for satellite altime- ter data and for successful forecasting of ocean eddies and the meandering of ocean currents and fronts.

\section{NRL Global Ocean Modeling System Motivation for NLOM-NCOM System}

NRL's global ocean prediction strategy, as discussed by Harding et al. (1999), is driven by the need for ocean models with the high horizontal resolution required to successfully simulate the variability of mesoscale features and the high vertical resolution required near the surface to resolve the physics of the upper ocean. On global scales it is not yet possible to run affordably one ocean model in real time that has the horizontal and vertical resolution needed to meet these requirements. Thus, the first generation global ocean prediction system uses a two-model approach based on NLOM and NCOM.

NLOM, forced by daily output from the Navy Operational Global Atmospheric Prediction System (NOGAPS; see Rosmond et al., this issue), assimilates altimeter-derived sea surface height ( $\mathrm{SSH}$ ) with the high horizontal resolution needed for the mesoscale dynamics and serves as an effective dynamic interpolator of the altimeter data in mapping this variability. NCOM, also forced by NOGAPS and deriving its mesoscale information from the 3-dimensional 


\section{Global Ocean Prediction Baseline}

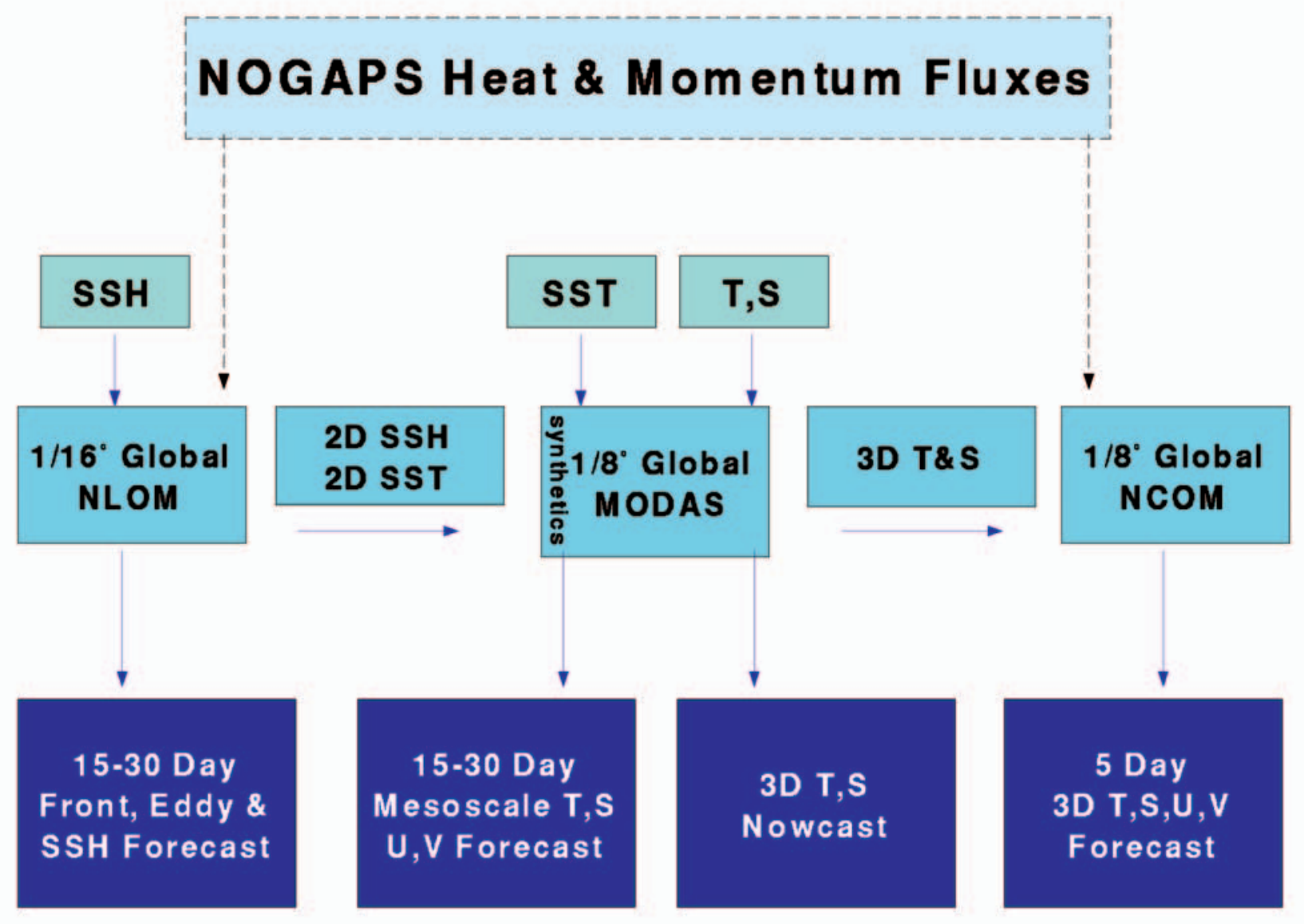

Figure 2. Wiring diagram of NRL global ocean prediction system baseline showing relationship between MODAS, NLOM, and NCOM modules and the role of each component in the overall system.

MODAS temperature and salinity profiles derived from the NLOM SSH and the MODAS SST analyses, provides a global oceanic boundary layer prediction capability from the open ocean and into the coast. With a sophisticated surface mixed-layer formulation (Mellor and Yamada, 1982) and the ability to run a fully global grid including the Arctic and continental shelves, NCOM can be used to provide boundary and initial conditions to nested higher resolution coastal models and can also be used for global air/sea interaction applications. Until NCOM, or other similar models, can run on operational computers at sufficient horizontal resolution to resolve the ocean mesoscale, we expect the two-model approach will be necessary.

Figure 2 shows a schematic of the entire global system emphasizing the individual roles of NLOM, MODAS, and NCOM. The analysis portion of the system is based on MODAS (Fox et al., 2001), which is now operational at NAVOCEANO. MODAS is an optimum interpolation analysis system with the ability to generate synthetic temperature and salinity profiles based on observed sea surface temperature (SST) and SSH. MODAS contains a global bimonthly database of regression coefficients relating deviations of SSH and SST from climatology to deviations of subsurface temperature from climatological profiles. This synthetic profile capability is part of a global climatology that extends into shallow water using only SST where the depth is $<200$ meters. The current operational global MODAS capability generates synthetic profiles based on $18^{\circ}$ global SSH and SST analyses performed daily at the NAVOCEANO Altimetry Data Fusion Center (ADFC; see Jacobs et al., this issue). The global MODAS capability will be upgraded to perform a full 3-D analysis by assimilating available in situ data and the analysis profiles will be used for assimilation into the global NCOM (discussed later).

Operational applications for the NLOM system include improved nowcasts (i.e. the current state of the ocean) and forecasts of mesoscale variability including 
major front and eddy systems like the Gulf Stream and Kuroshio Extension. These will be used by NAVOCEANO to improve their capability to depict the locations of oceanic fronts and eddies. Also, accurate highresolution NLOM SSH products will improve MODAS 3-D temperature and salinity synthetic profiles, thus providing a more accurate and dynamically realistic initialization for global NCOM. NLOM provides a "first of its kind" forecast capability for ocean fronts and eddies, including the ability to generate up to 30day forecast MODAS synthetic profiles generated from NLOM's high-resolution SSH and SST fields.

NCOM will provide an ocean nowcast/forecast capability for up to 5-days that will be used as boundary conditions for nested high-resolution fixed and relocatable coastal forecasting systems. Also, NCOM's more sophisticated surface mixed layer formulation should allow the cycling of NCOM forecasts of SST and mixed-layer depth with the MODAS SST analysis to improve the upper ocean nowcasts. Surface current nowcasts and forecasts from NCOM will be used for search and rescue operations and also for optimum track ship routing. Studies are currently underway at NRL evaluating NCOM performance for upper ocean nowcast and forecast skill. The skill assessment will provide measures of performance and model error that can be used to improve the real-time assimilation and provide a baseline for future upgrades to the global modeling system.

\section{NRL Layered Ocean Model System}

The NRL Layered Ocean Model is a descendent of the primitive equation model by Hurlburt and Thompson (1980). Since then the capability of the model has been greatly expanded (Wallcraft, 1991; Wallcraft and Moore, 1997; Moore and Wallcraft, 1998).

The model has a free surface, realistic topography and a nearly global domain that extends from $72^{\circ} \mathrm{S}$ to $65^{\circ} \mathrm{N}$ for all deep water $(>200 \mathrm{~m})$ regions and selected straits (e.g. Tsushima). The horizontal resolution of each model variable is $1 / 16^{\circ}$ in latitude by ${ }^{45} / 512^{\circ}$ in longitude and at this resolution, the model is eddy-resolving. The model is thermodynamic, meaning it contains a horizontally and temporally varying density variable that can be modified by known physical processes (i.e. atmospheric thermal forcing, advection, diffusion, entrainment) or by relaxation to a density climatology such as MODAS. The latter helps NLOM maintain accurate SSH. Unlike models with fixed levels in the vertical, NLOM's density relaxation does not damp the $\mathrm{SSH}$ anomalies because most of the information about these anomalies is carried in NLOM's layer thickness variations. For example, NLOM maintained a Rossby wave generated by the 1982-83 El Niño for at least a decade (Jacobs et al., 1994) without oceanic data assimilation except for relaxation to climatological density. The model equations and additional details concerning NLOM can be found in Hurlburt et al. (1996), Metzger and Hurlburt (1996), Moore and Wallcraft (1998) and
Shriver and Hurlburt (1997). A bulk mixed layer model and sea surface temperature was added to NLOM, Wallcraft et al. (2002), and is part of the system transitioned to NAVOCEANO.

The model was spun up over a 10 year period from 1990-2000. During the spin up a hybrid wind was used consisting of a combination of Fleet Numerical Meteorology and Oceanography Center (FNMOC) NOGAPS and Hellerman and Rosenstein (HR,1983) surface stresses where the long-term mean (August 1990-July 1999 for FNMOC) is subtracted from the FNMOC stresses and replaced with the HR annual mean. European Centre for Medium-Range Weather Forecasts thermal forcing was used from 1990-1997, followed by a switch to NOGAPS thermal forcing in 1998. In 1997 (1998), SSH (SST) assimilation began. This was continued until October 2000, when the system was transitioned to NAVOCEANO where it has been running in real time since 18 October 2000 and became an operational product on 27 September 2001. It is updated daily as part of the operational run stream with SSH and SST assimilation and is forced by realtime NOGAPS wind and thermal forcing.

\section{NLOM Data Assimilation}

The NLOM system assimilates both SSH and SST but using different methods. The SSH assimilation is performed daily and is an optimum interpolation (OI) based data assimilation scheme. The technique uses an OI deviation analysis with the model as the first guess, the statistical inference technique of Hurlburt et al. (1990) for vertical projection, geostrophic balance for velocity deviations outside an equatorial band, and incremental insertion to further reduce inertia-gravity wave generation (Smedstad and Fox, 1994). Jacobs et al. (1999) calculated the spatially varying, anisotropic mesoscale covariance functions for the OI analyses from TOPEX/POSEIDON and ERS-2 data over 1993-99. The SST assimilation is performed by relaxing NLOM SST to the real time MODAS global SST analysis performed daily at NAVOCEANO.

The assimilation cycle for the operational system goes back three days in time and uses analysis wind and thermal forcing as SSH and SST data are assimilated up to the nowcast time. In the process the steps for $\mathrm{SSH}$ in the paragraph above are repeated once a day. This allows the use of newly received data and more accurate altimeter data that get updated, as more precise orbit calculations are available to the ADFC. This approach improves the accuracy of nowcasts used to initialize model forecasts. The system performs a daily 4-day forecast, except for once a week when a 30-day forecast is made. During the forecast period, SST is relaxed to climatologically corrected persistence of the nowcast SST with a relaxation time scale of $1 / 4$ the forecast length (i.e. 1 day for a 4-day forecast and 1 week for a 4-week forecast). This is a necessary step for the longterm (30-day) SST forecasts because the forecast atmospheric thermal forcing is only available out to five days. 
Research at NRL has shown this method produces a more accurate SST forecast. During a 30-day forecast, the position of oceanic fronts, current/frontal meanders and eddies can change substantially. The SST relaxation is weak enough that it allows the model to keep the SST forecasts of these features in better phase with the forecasts of SSH and surface currents than climatologically corrected persistence. There is no relaxation for SSH because the model is used to forecast the movement of fronts and eddies due to flow instabilities that are more sensitive to initial conditions than to atmospheric forcing.

\section{NRL Coastal Ocean Model System}

NCOM Version 1.0 (Martin, 2000) is based primarily on two earlier ocean models, the Princeton Ocean Model (POM; Blumberg and Mellor, 1983; Blumberg and Mellor, 1987) and the Sigma/Z-level Model (SZM; Martin et al., 1998). SZM is similar to POM, but differs in several ways; most notably it uses a hybrid vertical coordinate system. The vertical grid is set up to offer a choice of sigma layers or z-levels, or some combination with sigma layers in the shallow water and z-levels in the deeper water.

Like NLOM, NCOM is designed to be a scalable, portable code that runs efficiently on different computational architectures. The model was designed to fit within the very specific code structure of the Coupled Ocean Atmosphere Mesoscale Prediction System (COAMPS) that provides for calls to (i.e., coupling between) both the atmospheric and ocean models within the same Fortran program (see Hodur et al. in this issue). Thus, NCOM is already set up for modeling coupled air-ocean systems. NCOM also provides for an arbitrary number of nesting levels within the same Fortran program.

The transition of global NCOM to NAVOCEANO is planned by the end of 2002. This version is on a curvilinear global grid extending from $80^{\circ} \mathrm{S}$ to a complete Arctic cap. This cap is a bipolar grid with poles over land at $47^{\circ} \mathrm{N}$ in North America and Asia. Global NCOM uses realistic topography including all continental shelves to depths $>5 \mathrm{~m}$. The planned operational grid resolution for global NCOM is $\sim 1 \%{ }^{\circ}$ in longitude by $\sim 16^{\circ} \mathrm{X} \cos \theta$ in latitude (where $\theta$ is latitude) except for the Arctic cap, which matches the longitudes of the spherical grid at $47^{\circ} \mathrm{N}$. This translates to $\sim 15-16$ $\mathrm{km}$ grid spacing at mid-latitudes or $\sim^{1} / 8^{\circ}$ in latitude near $45^{\circ} \mathrm{N}$, the nominal mid-latitude grid resolution in degrees.

Currently there are two versions of global NCOM that have been tested by NRL and results from both will be shown. The first version is a $14^{\circ}$ (at $45^{\circ} \mathrm{N}$ ) global model with 20 sigma-z levels (6 sigma, $14 \mathrm{z}$ ). It has been run in real-time data-assimilative mode since August 2000. This model is forced using NOGAPS 3hourly wind stresses and heat fluxes and assimilates the MODAS global SST analysis and 3-D temperature and salinity synthetic profiles derived from the global
MODAS SSH and SST analyses. Currently this version produces a 2-day forecast daily as a testbed for the planned 5-day operational forecast. The $1 / 8^{\circ}$ (at $45^{\circ} \mathrm{N}$ ) version has 40 sigma-z levels (19 sigma, $21 \mathrm{z}$ ) and has been running in real-time data-assimilative mode since October 2001 forced with NOGAPS 3-hourly wind stresses and heat fluxes. The $1 / 8^{\circ}$ model assimilates SST from MODAS and has been tested with assimilation of synthetic temperature and salinity derived from both the global MODAS SSH analysis and the $1 / 16^{\circ}$ global NLOM SSH nowcast.

\section{NCOM Data Assimilation}

The data assimilation for the $1 / 8^{\circ}$ global NCOM is accomplished via two mechanisms: adjustment of surface heat and freshwater fluxes and insertion of subsurface temperature and salinity profiles. In either case, the strength of assimilation is controlled by a gridded weighting function that reflects the relative confidence between the model and data. The slow data insertion technique allows the model to incrementally adjust to the data with minimal dynamic disruption. Preparation of data fields is independent of the NCOM assimilation itself, allowing the model to accommodate a variety of approaches that prepare the observational analyses.

Present data preparation for $1 / 8^{\circ}$ global NCOM begins with SST fields from MODAS 2-D (the operational $1 / 8^{\circ}$ global MODAS SST analysis performed daily at NAVOCEANO) and SSH from $1 / 16^{\circ}$ global NLOM. Note that MODAS 2-D also produces a $18^{\circ} \mathrm{SSH}$ analysis from altimeter data, but in this global model application the NLOM SSH field is used to take advantage of the improved nowcast skill of the NLOM dynamics over the MODAS statistical model. Subtracting the NLOM climatological mean SSH from the daily SSH yields a SSH deviation, which is passed along with the MODAS 2-D SST to the MODAS module for calculation of synthetic profiles of temperature and salinity. SSH does not presently provide value-added to the MODAS synthetic profiles in shallow water. Therefore, a mask, which combines a smoothed topography with constraints imposed by the boundaries of the NLOM domain, determines the extent to which SSH is used in estimating subsurface temperature. Combined $\mathrm{SSH}$ and SST regressions are used fully where the mask depth is greater than $600 \mathrm{~m}$, while MODAS SST-only regressions are used in regions with mask depth less than $200 \mathrm{~m}$, not covered by the NLOM domain. Profiles are based on smoothly blended regressions for regions of intermediate mask depth.

Salinity is estimated from temperature according to local climatological T-S regressions. At this stage available in situ observations may be assimilated into the 3$\mathrm{D}$ analyses. After converting temperature to potential temperature, the 3-D potential temperature and salinity fields are interpolated to the model grid, and masked according to the model land and topographic depth. Surface salinity is extracted and paired with the interpolated SST for adjusting the surface fluxes. 
In an operational model run for nowcast time $T, 18^{\circ}$ global NCOM is initialized with the previous analysis for time T-3 days to allow the analysis to take advantage of the more accurate SSH analysis from NLOM, which does a daily re-analysis for time T-3 to T. Surface heat and salinity fluxes are adjusted by the data-model differences times a flux rate. Subsurface temperature and salinity are nudged toward the data according to a 3-D weighting factor.

\section{Real-time results $\mathrm{NLOM}$ \\ NLOM SSH nowcast comparisons with NAVO- CEANO frontal analyses}

The $1 / 16^{\circ}$ global NLOM has been running in real time with SSH and SST assimilation since 18 October 2000 and became an operational product of NAVOCEANO on 27 September 2001. NRL has developed evaluation software and has been monitoring the performance of the system to establish the baseline performance measurements for the first generation operational system. At the present time only satellite data are assimilated, which allows comparison with independent in situ data from buoys and expendable bathythermographs (XBTs). In the near future, in situ data will be assimilated into the MODAS/NLOM/NCOM system, but for now will be used to determine the baseline performance of the entire system. In real-time, the wealth of the ocean data available comes from global satellites and these data will be the major contributors to model analysis and forecast skill, so analysis of the system performance based only on satellite data is an important, but also very demanding evaluation.

One evaluation of the NLOM system is its ability to nowcast the positions of major fronts and eddies on the global scale. The Warfighting Support Center (WSC) at NAVOCEANO relies on satellite Infra-Red (IR) SST data to locate fronts and eddies for the global ocean and releases frontal analysis products to the fleet. The NLOM system will allow the WSC analysis to use daily nowcasts and animations of SSH as another powerful guidance tool to improve the quality of frontal analysis products. This is particularly significant because $\mathrm{SSH}$ is a better indicator of subsurface frontal location than SST. An example where this has an impact is discussed later in this subsection. Specifically, NLOM provides a daily map of the ocean mesoscale SSH field that can be used as a tool to help the WSC interpret cloud filled IR images. In addition, by using animations of the NLOM SSH field, the analyst can better track front and eddy movements to help analyze the space and time continuity of the ocean mesoscale in areas where frontal analysis is required.

Figure 3 shows the NLOM SSH nowcast for the Gulf Stream overlaid with a portion of the daily WSC frontal analysis product for June 4, 2001 (Figure 3a) and for June 11, 2001 (Figure 3b). One must be careful in interpreting these results because of the uncertain quality of the WSC frontal analysis. Due to clouds, the analyst may not have seen the front for several days and may be depending on a previous (older) frontal analysis or may be analyzing for a shallow surface feature of SST off the Gulf Stream. In this case for June, the WSC had good quality images and the frontal position has high confidence along most of the Gulf Stream path. However, the WSC analysis did not use the NLOM model output and can be considered a completely independent analysis.

For both June 4 and June 11, 2001, the NLOM Gulf Stream pathway has good agreement with the WSC frontal analysis. Both NLOM and the frontal analysis agree on the position and shape of the meanders at $67^{\circ} \mathrm{W}$ and $53^{\circ} \mathrm{W}$, features that change their shape between June 4 and June 11. During this period the meanders deepen, as seen in both the model and the frontal analyses. The model also captures a warm ring shedding event near $62^{\circ} \mathrm{W}$ that is verified by the WSC frontal analysis. On June 4, both products indicate a deep ridge near $60^{\circ} \mathrm{W}$ that bends back toward the west and on June 11, both indicate that a warm eddy has shed from the Gulf Stream. There is also good agreement on a trough at $47^{\circ} \mathrm{W}$, which indicates that the model has a realistic pathway from Cape Hatteras to the Grand Banks when compared with the WSC frontal analysis. Additional comparisons are available on the NLOM web site at http://www7320.nrlssc.navy.mil/global_nlom.

The real value of the NLOM SSH frontal analysis will be during times when the IR data is cloudy or when a subsurface front is masked by uniform SST as occurs for the Gulf of Mexico Loop Current in summer, for example. The WSC plans to use the NLOM product as a first guess for their frontal analysis product. The errors in the WSC analyses are mainly due to IR imagery that is difficult or impossible to interpret because of clouds or to lack of a frontal signature in SST. NLOM provides a useful guidance product for the WSC analysts to improve the frontal analysis in areas where it is cloudy or during the warmer months when the fronts lose their surface SST signature.

\section{NLOM Sea Surface Height for deriving MODAS synthetics}

As discussed earlier, one of the operational uses for the $1 / 16^{\circ}$ global NLOM is to provide accurate high-resolution SSH nowcasts with realistic mesoscale features to derive MODAS synthetic temperature and salinity profiles. The increased accuracy of the profiles will help to improve the full MODAS 3-D analysis, which will then be assimilated into the global NCOM system providing an improved initialization for the NCOM forecasts. Since NLOM has the needed resolution to act as a dynamic interpolator of the satellite altimeter data, it provides the global NCOM with a more dynamically correct initialization than MODAS. Some of the advantages of the higher resolution NLOM synthetics as input to global NCOM include, better defined ocean fronts, better definition of boundary currents, western 

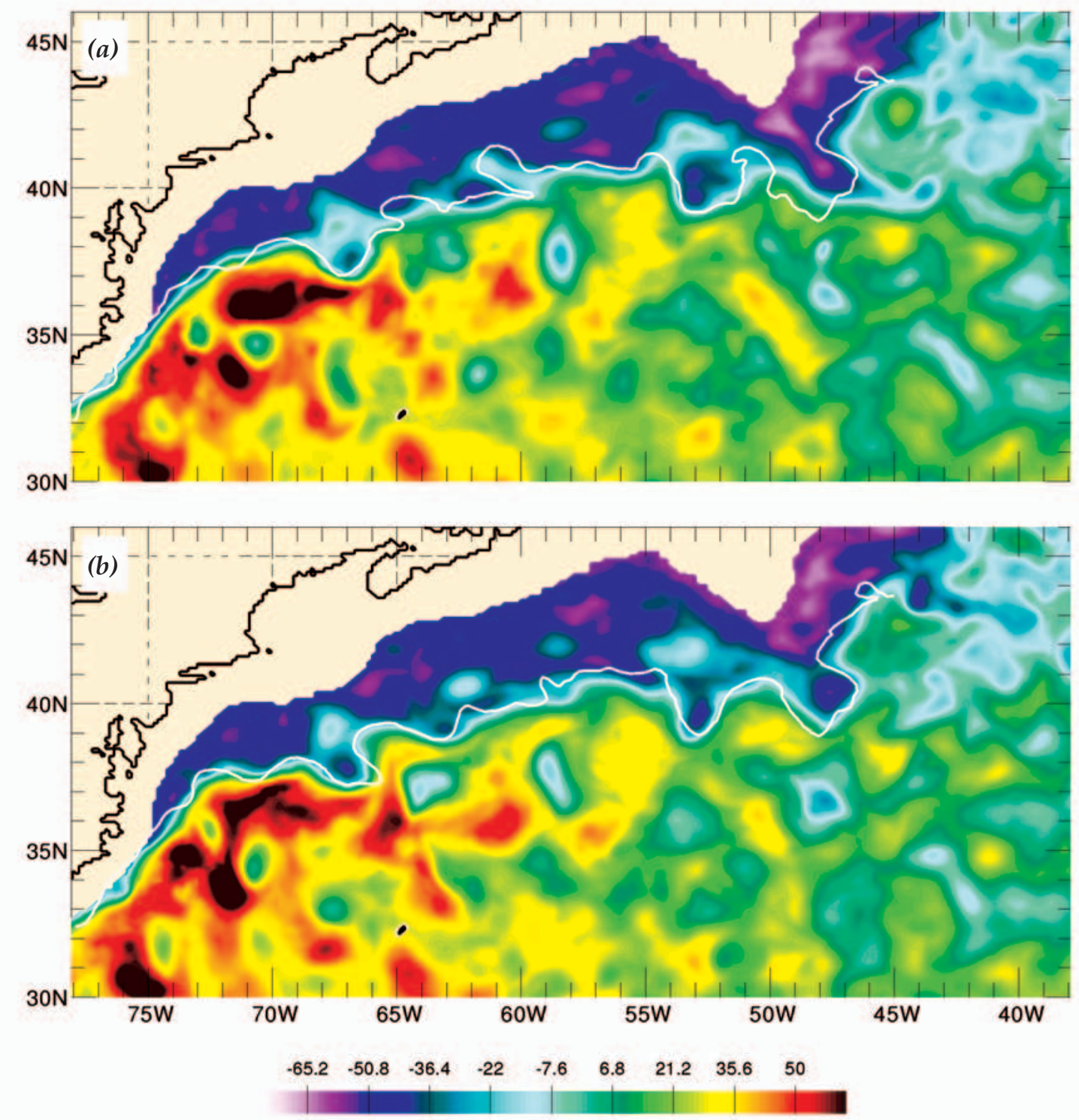

Figure 3. SSH analysis (nowcast) in the Gulf Stream region from the real-time $1 / 16^{\circ}$ global NLOM for a) June 4, 2001 and $\boldsymbol{b}$ ) June 11, 2001. Superimposed on each is an independent Gulf Stream north wall frontal analysis determined from satellite IR imagery (white lines) by the Naval Oceanographic Office for the same days. The color palette was chosen to emphasize the location of the Gulf Stream and associated eddies.

boundary currents that more realistically penetrate into the basin, more realistic SSH gradients across fronts, and more realistic shapes and size of eddies.

Figure 4 shows the results of comparisons between MODAS and NLOM generated 3-D synthetics vs. independent XBTs from the NLOM Operational Test performed at NAVOCEANO. A total of about 4900 XBTs and conductivity-temperature-depth (CTD) measurements collected worldwide in January and February 2001 were used for independent evaluation of the synthetic profiles calculated using the MODAS 2-D SSH field and the NLOM SSH field. None of the measured profiles were assimilated into either MODAS 2-D or NLOM. The test was to compare the root mean square
(RMS) error $\left({ }^{\circ} \mathrm{C}\right)$ of synthetic temperature profiles calculated from MODAS and NLOM SSH (vs. XBT temperature profiles). Errors were calculated as the difference between a measured profile and its nearest synthetic neighbor at a series of standard depths. This test was performed on the entire data set (Figure 4a), and again on a subset of the data (Figure $4 \mathrm{~b}$ ) that consists of those XBTs ( 800) where the corresponding nowcast SSH (both NLOM and MODAS) was greater than $7 \mathrm{~cm}$ different from climatology. The subset criteria were chosen to highlight the larger improvement of NLOM and MODAS over climatology in areas where there was observed mesoscale variability.

Figure 4a shows the RMS error for all the XBTs vs. 
operational MODAS 2-D, NLOM and climatology (the latter being the accepted first order comparison for ocean analysis systems). The results indicate that NLOM has equal or lower RMS error than MODAS down to $\sim 400$ meters and is basically the same at the lower depths, but both NLOM and MODAS 2-D are
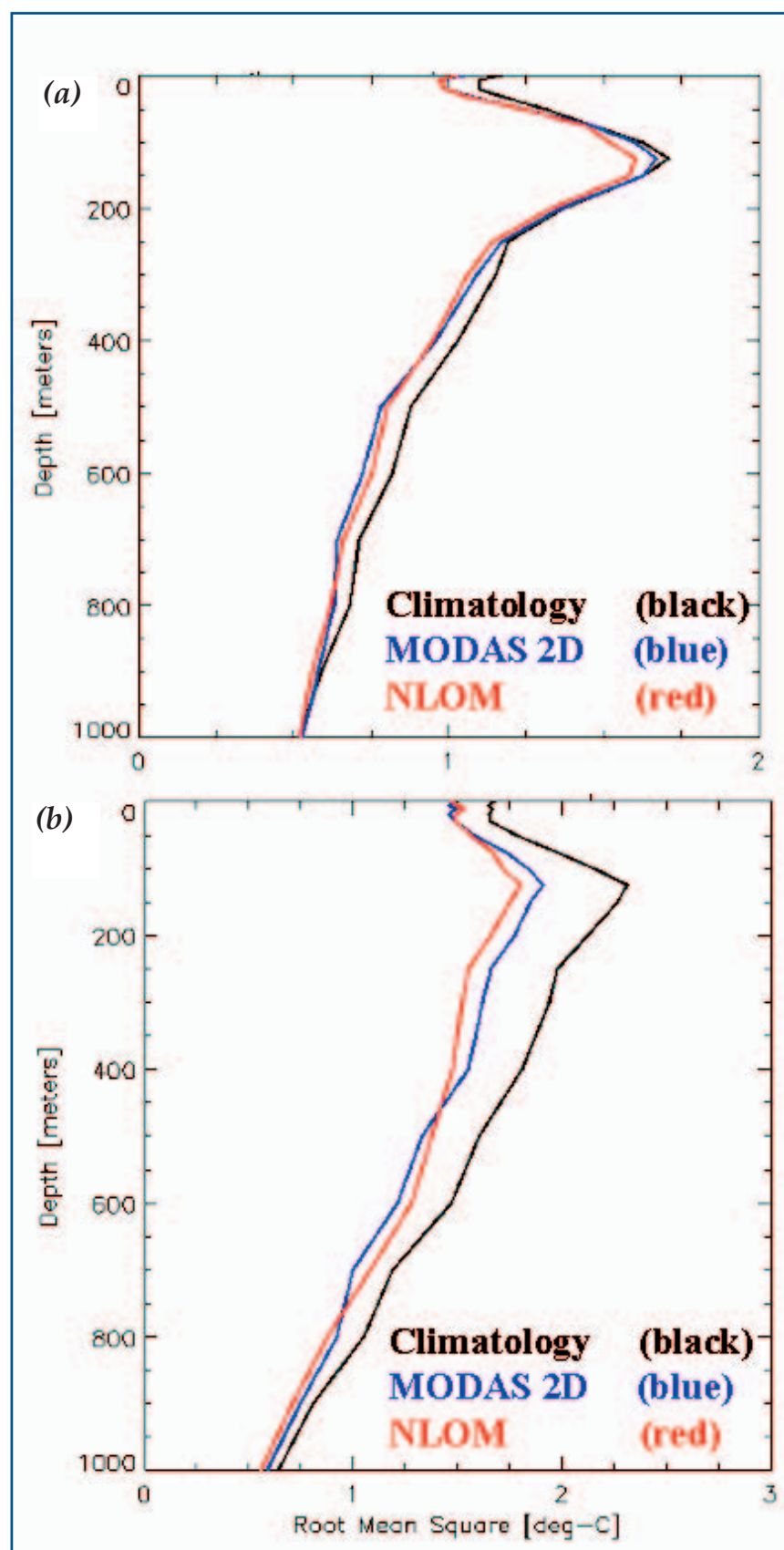

Figure 4. RMS temperature error $\left({ }^{\circ} \mathrm{C}\right)$ vs. depth (meters) for MODAS climatology (black) and MODAS synthetic profiles calculated using MODAS 2-D SSH (blue) and NLOM SSH (red) compared with a) 4900 unassimilated global XBTs from January and February, 2001 and b) a subset of the global XBTs ( 800) where MODAS and NLOM SSH at the XBT location were both $>7$ centimeters away from the climatological SSH. superior to climatology. Figure $4 \mathrm{~B}$ is the result for the subset of XBTs showing the comparison with SSH for NLOM and MODAS for cases where there was observed mesoscale variability $>7 \mathrm{~cm}$ from climatology. For this case, the value added of NLOM and MODAS 2-D is much more apparent. Both MODAS and NLOM synthetics have lower RMS error than climatology and similar to the previous case with all the data, NLOM has equal or lower errors than MODAS 2-D down to 450 meters. In this case, MODAS 2-D is slightly better from 500 to 800 meters with the two products essentially the same down to 1000 meters.

\section{NLOM SSH forecasts}

The ability of NLOM to forecast SSH and the positions of major fronts and eddies represents a new Naval product available for future operational planning and to help users gauge the quality of the product. The future positions of major ocean fronts can give the warfighter guidance on how changes in the ocean environment might affect future missions. An accurate forecast of SSH would allow the Navy to predict changes in locations of mesoscale features (fronts and eddies) that affect the 3-D temperature and salinity field by using the predicted NLOM SSH and SST to derive MODAS synthetic profiles. Changes in the 3-D ocean environment would change acoustic conditions in the deep water and could be used as a planning tool for future deployment of operational fleet assets or when a fleet asset was unable to receive timely products.

Figure 5 shows a SSH example of a nowcast for January 3, 2001 (Figure 5a), the 15-day forecast (Figure $5 b)$ and verifying analysis for January 18, 2001 (Figure $5 c$ ), and the 30-day forecast (Figure 5d) and verifying analysis (Figure 5e) for February 2, 2001 for the Kuroshio Extension region. The NLOM system performs a 30-day forecast once a week and the verification statistics are calculated by comparing the model daily prediction to the corresponding validating analysis for that same day. The Kuroshio is in "meander mode" near $140^{\circ} \mathrm{E}$ and in this case the model predicts a widening of the meander after 30 days, which is also seen in the verifying analysis. The model also correctly predicts the growth of the ridge at $149^{\circ} \mathrm{E}$ and the deepening of the trough meander near $147^{\circ} \mathrm{E}$, as well as the movement of the warm and cold eddies near $150^{\circ} \mathrm{E}$ that will be evident in the cross-section (Figure 7) discussion.

Figure 6 shows mean 30-day forecast verification statistics for SSH RMS error and SSH anomaly correlation versus forecast length for the 19 monthly forecasts made each week from December 20, 2000 to May 16, 2001. Anomaly correlation is a standard statistical correlation of deviations from the mean SSH that is similar to that used in atmospheric forecast verification where values $>0.6$ are considered skillful (Murphy and Epstein, 1989). Results are shown for the entire global domain (Figures $6 \mathrm{a}$ and $6 \mathrm{~b}$ ), the Gulf Stream region (Figures $6 \mathrm{c}$ and $6 \mathrm{~d}$ ), and the Kuroshio region (Figures $6 \mathrm{e}$ and $6 \mathrm{f})$. These statistics are calculated by comparing 


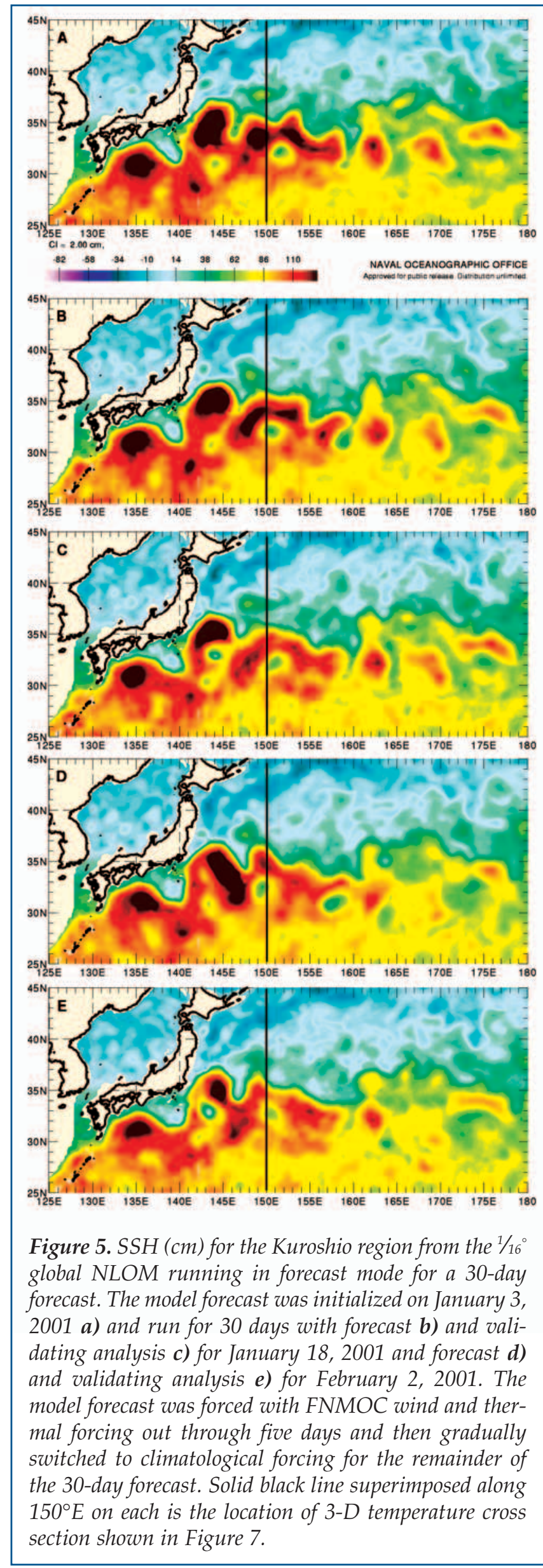

the model forecast SSH field vs. the analysis SSH from NLOM valid on the day of the forecast. For both RMS error and anomaly correlation on the global domain, the model is beating persistence and climatology (for RMS error) with the anomaly correlation showing model skill out beyond 30 days.

Verification statistics for the Gulf Stream and Kuroshio areas indicate the skill of the model in regions dominated by flow instabilities and high SSH variability. In the Gulf Stream area, NLOM shows forecast skill that is less than the global case. In terms of RMS SSH error, NLOM beats persistence in the Gulf Stream out to 30 days. However, the SSH anomaly correlations indicate that NLOM typically has skill for less than 20 days. The Kuroshio results are better than the Gulf Stream and more similar to the global case with skill out beyond 30 days. As expected, the RMS error is higher in the Kuroshio than the global domain due to the high SSH variability that is observed in that area due to flow instabilities. Although not shown here, NLOM SST prediction measures are also calculated for 30-day forecasts and show that NLOM on average beats both persistence and climatology for the global domain because of the relaxation to climatologically corrected persistence as discussed earlier. Real-time SST prediction measures are similar to those shown for SSH. In addition, nowcast SST comparisons with unassimilated buoy data are updated daily and available on NRL's public NLOM website discussed earlier.

The difference in model skill between the Kuroshio and Gulf Stream is due to the resolution of the NLOM system and the dynamics of the two strong western boundary currents. As stated earlier, the results shown here are consistent with other NRL research (Hurlburt and Hogan, 2000), which indicates that at least $1 / 32^{\circ}$ is required for proper simulation of the Gulf Stream. The forecast statistics indicate that the Kuroshio dynamics are well represented by the model. For most of the ocean, $1 / 16^{\circ}$ resolution is enough to allow skillful forecasts of SSH. Even though the current system does not show 30-day skill for the Gulf Stream, the results indicate that the system has skill to at least 18 days. NRL is currently working on a $1 / 32^{\circ}$ global system, which is a possible future upgrade to the NLOM system, and this system should improve the Gulf Stream results.

Figure 7 shows an example of MODAS synthetic temperature and salinity calculated from the NLOM SSH and SST analyses and forecasts on January 3 (Figure 7a), January 18 (Figures $7 \mathrm{~b}$ and 7c), and February 2, 2001 (Figures 7d and 7e) for the Kuroshio cross section along $150^{\circ} \mathrm{E}$, depicted by the solid black line in Figure 5. Similar to the SSH forecast comparison in Figure 5, the 15 and 30-day forecasts are compared to the corresponding analysis valid on the forecast day. There are several interesting events that are correctly captured by the model forecast. The Kuroshio front is displaced to the north during the forecast as a ridge meander builds along $150^{\circ} \mathrm{E}$. On January 3, 2001, (Figure 7a) the Kuroshio front is at $35^{\circ} \mathrm{N}$ and moves 

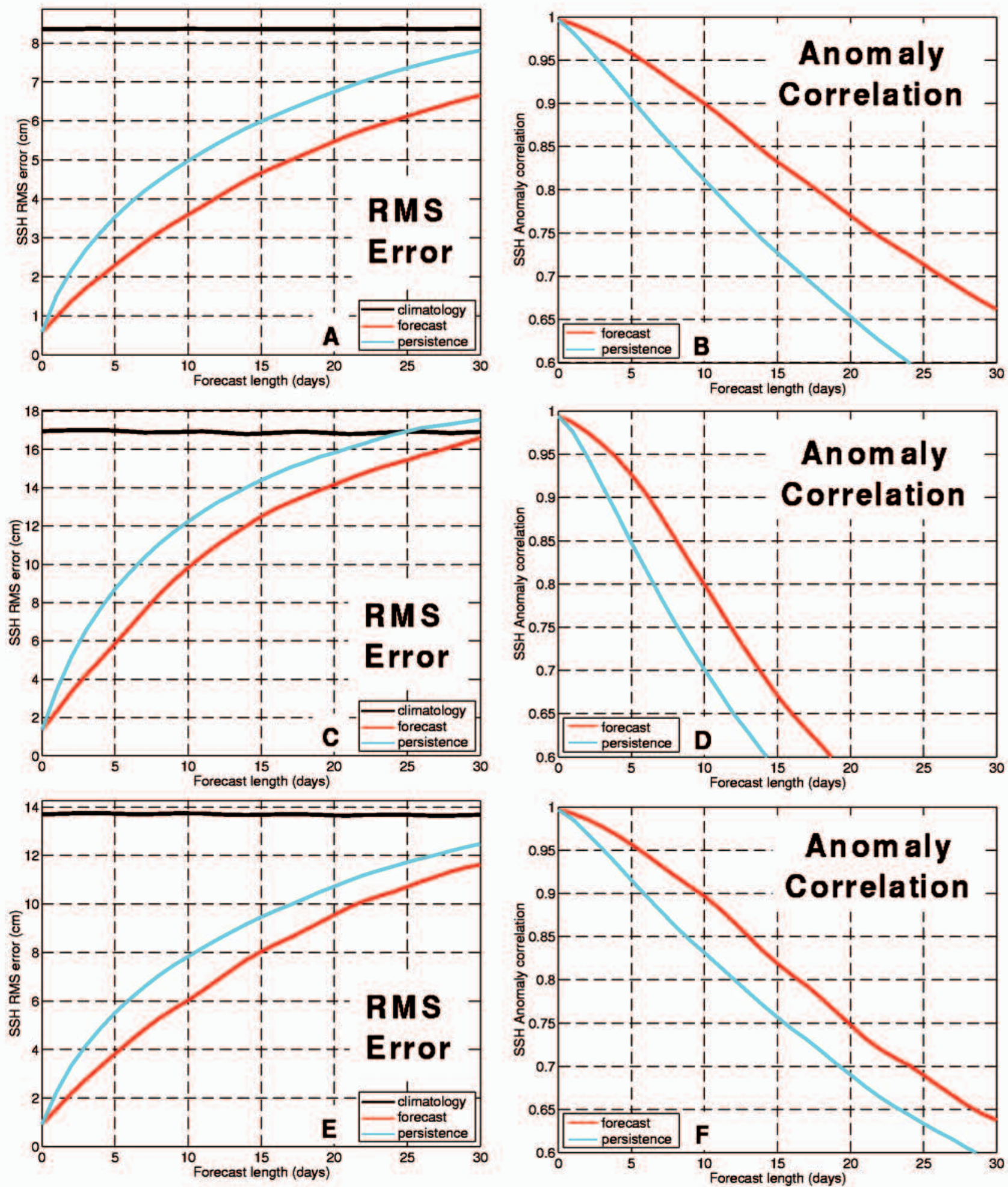

Figure 6. Mean SSH forecast verification statistics for 19 weekly 30-day forecasts from December 20, 2000 to May 16, 2001 for the $1 / 16^{\circ} \mathrm{global}$ NLOM. Left column shows mean SSH RMS error (cm) and right column shows mean anomaly correlation vs. forecast length (days) for NLOM forecast (red curve), persistence forecast (blue curve) and climatology forecast (black curve). The top row $\boldsymbol{a}, \boldsymbol{b}$ ) is for the global domain, the middle row $\boldsymbol{c}, \boldsymbol{d})$ is the Gulf Stream region and the bottom row $\boldsymbol{e}, \boldsymbol{f}$ ) is for the Kuroshio region. 


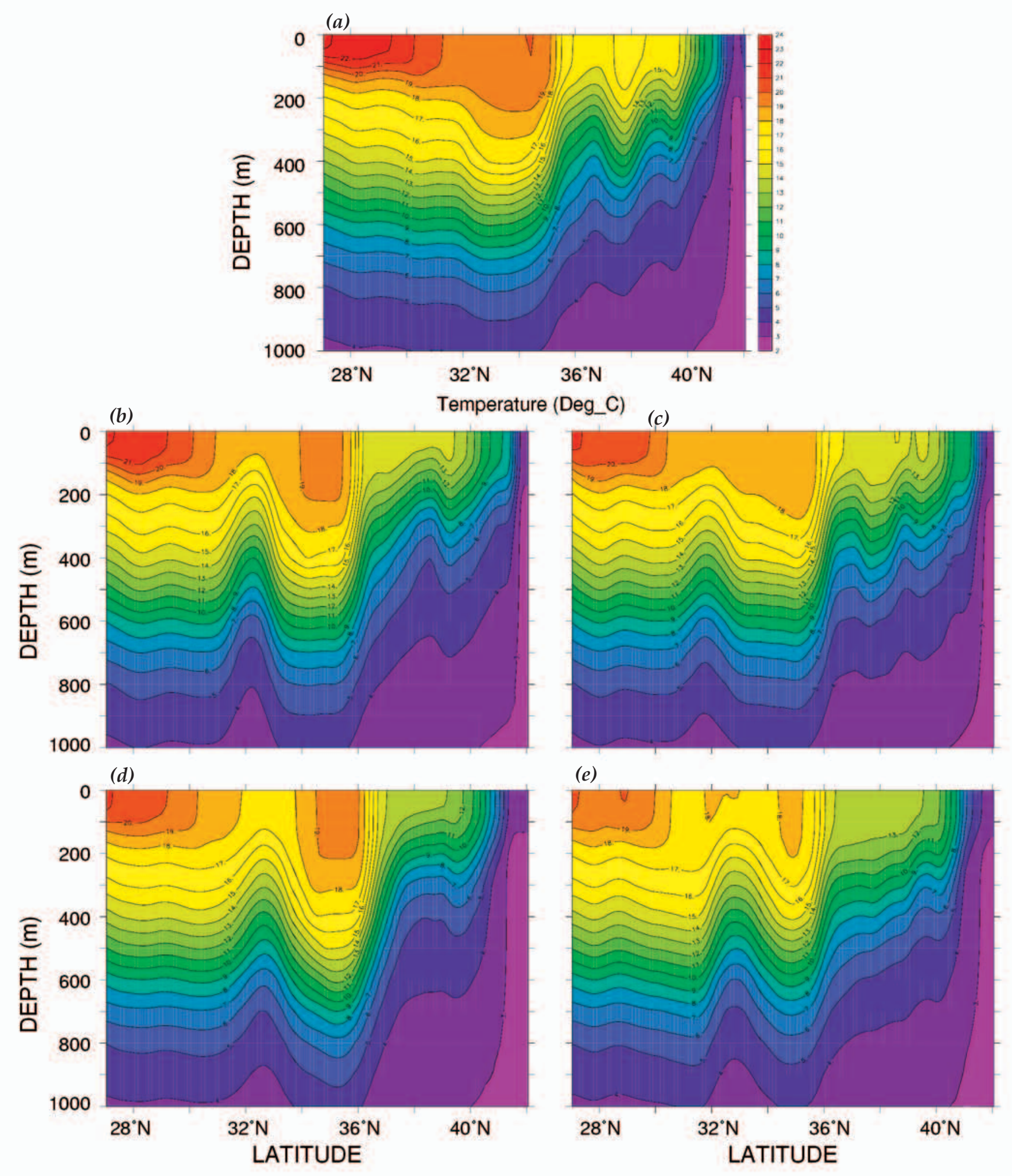

Figure 7. Temperature $\left({ }^{\circ} \mathrm{C}\right)$ vs. depth along $150^{\circ} \mathrm{E}$ for the Kuroshio region derived from $1 / 16^{\circ}$ global NLOM SSH and SST fields using the MODAS synthetic climatology (statistics derived from the historical hydrographic database). The model forecast was initialized on January 3, $2001 \boldsymbol{a}$ ) and run for 30 days with forecast $\boldsymbol{b}$ ) and validating analysis $\boldsymbol{c}$ ) for January 18, 2001 and forecast $\boldsymbol{d}$ ) and validating analysis e) for February 2, 2001. 
north of $36^{\circ} \mathrm{N}$ on February 2, 2001, which is seen in both the analysis (Figure 7e) and model forecast (Figure 7d). Also, a warm ring seen in the analysis near $38^{\circ} \mathrm{N}$ on January 3 is not visible in the model forecast or verifying analyses on January 18 or February 2 as the eddy has propagated to the west during the forecast period. Similarly, a cold eddy that was not in the cross section on January 3 is evident near $32^{\circ} \mathrm{N}$ in both the forecast and analysis on January 18 and February 2. This case study indicates how the 3-D temperature, and consequently the derived sound speed can change and it highlights the value of a skillful long-range forecast able to predict possible oceanographic and acoustic changes in a future operational area.

\section{NCOM}

\section{Global NCOM SST prediction measures}

One of the important operational uses for global NCOM is for short-term predictions of SST and mixedlayer depth with high vertical resolution. Using a more sophisticated upper ocean mixed-layer formulation, NCOM is designed for shorter forecasts (5-7 days) and uses thermal forcing from the operational NOGAPS model. This contrasts with the NLOM SST prediction capability designed for long-term (30 day) forecasts and depending on a weak relaxation to a climatologically corrected persistence because there is no skillful long-term atmospheric heat flux prediction capability out to 30 days. The expected NCOM skill for short-term mixed layer prediction, including SST forecasts, also provides the potential for its use as part of a global coupled air/ocean system and as a first guess to the MODAS analysis in a cycling analysis/forecast system.

As a testbed for the development of the $1 / 8^{\circ}$ global NCOM capability, NRL has run a real-time $14^{\circ}$ global version of NCOM since August 2000 that produces a daily nowcast and 2-day forecast. SST prediction measures are similar to those used for NLOM SSH where the SST forecast is compared to the corresponding analysis for the same day. Figure 8 shows the results for 40 daily

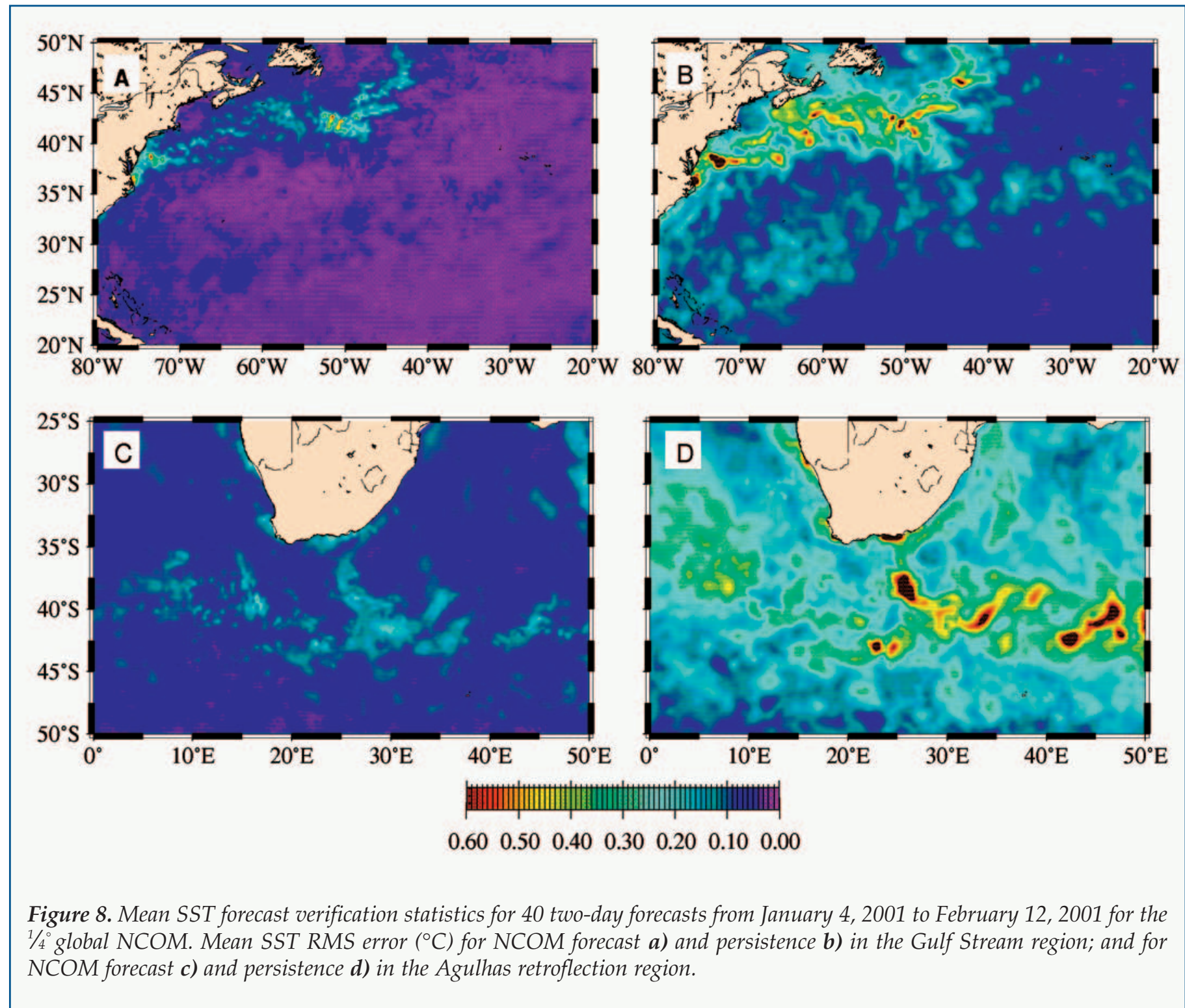



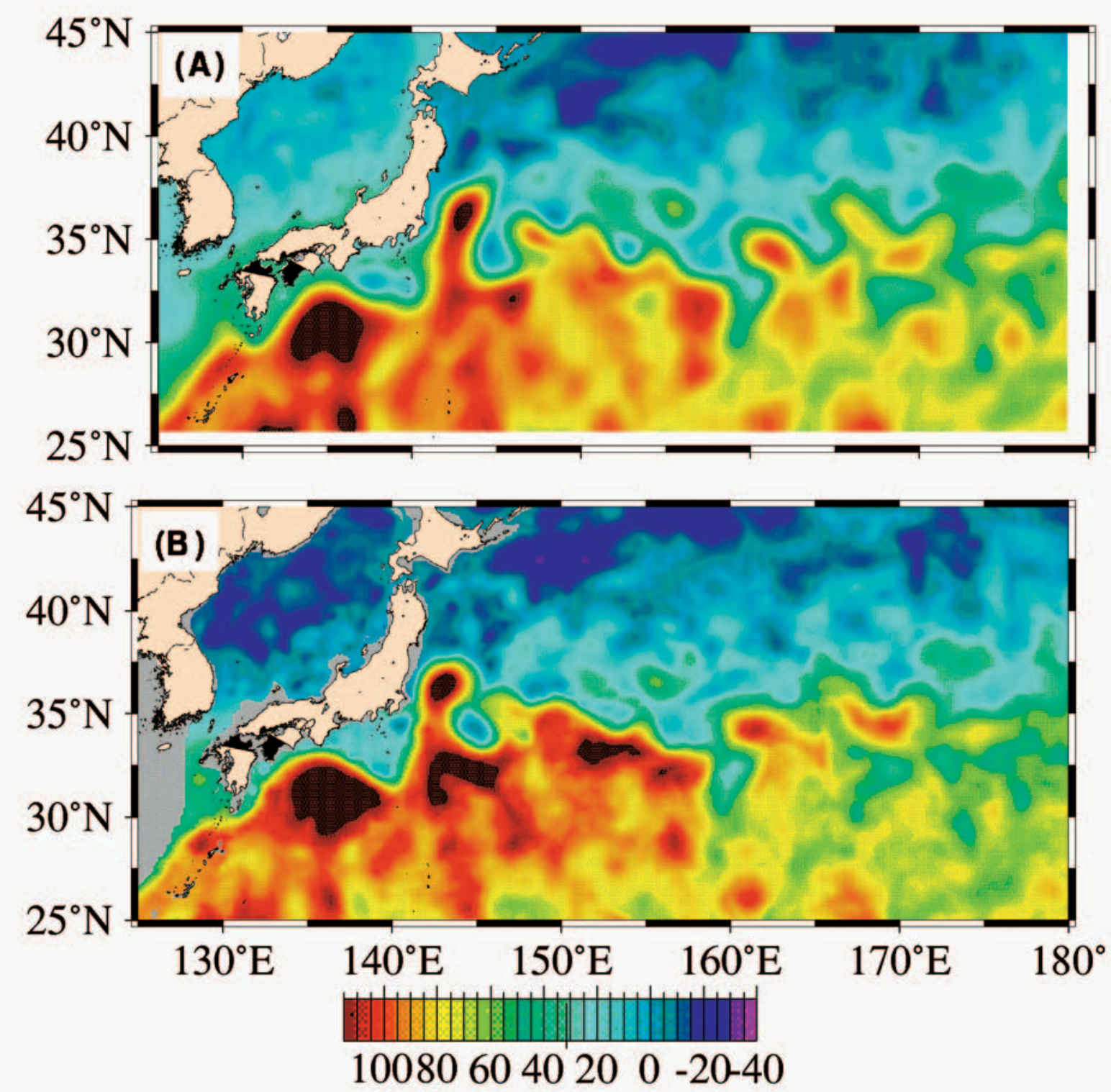

Figure 9. SSH (cm) nowcast for the Kuroshio region on May 19, 2001 from a) $1 / 8^{\circ}$ global NCOM and $\left.\boldsymbol{b}\right) 1 / 16^{\circ}$ global NLOM. NCOM model assimilates MODAS synthetic temperature and salinity profiles derived using the NLOM SSH field.

forecast cycles from January 4 to February 12, 2001. Figure $8 \mathrm{a}$ and $8 \mathrm{~b}$ are the mean RMS error $\left({ }^{\circ} \mathrm{C}\right)$ for the model forecast (A) and persistence (B) in the North Atlantic region. The forecast has lower errors than persistence throughout the region with the model showing highest skill in the area of the Gulf Stream front. Similarly for the Agulhas retroflection area (Figures 8c and $8 \mathrm{~d}$ ), the model RMS error is lower than persistence throughout the basin with highest skill in areas of frontal instabilities.

These results are consistent globally and for different seasons. This is a very encouraging result for SST prediction skill and comparable testing will be done with the $1 / 8^{\circ}$ global NCOM. In addition, the evaluation software that has been developed for NLOM can be used for the NCOM system to evaluate skill levels for short-term SSH and 3-D temperature prediction skill.

\section{$1 / 8^{\circ}$ Real-time Global NCOM}

The $1 / 8^{\circ}$ global NCOM system is planned for transition to NAVOCEANO and has been running in realtime since 26 October 2001. The system is forced by FNMOC NOGAPS and assimilates SST data as well as 3-D temperature and salinity profiles from the MODAS synthetic climatology using the $1 / 16^{\circ}$ global NLOM SSH and the $1 / 8^{\circ}$ MODAS 2-D SST analyses in generating the subsurface synthetics.

Figure 9 shows a result from the $1 / 8^{\circ}$ global NCOM in the Kuroshio region for May 19, 2001, when NCOM was running in near real-time. Figure 9 a is the NCOM 
SSH nowcast and Figure $9 \mathrm{~b}$ is the corresponding $\mathrm{SSH}$ nowcast from the real-time $1 / 16^{\circ}$ global NLOM. The NLOM SSH field was used by MODAS to calculate the synthetic temperature and salinity profiles that were assimilated into the global NCOM. The results indicate that the NCOM SSH field matches very well with NLOM, i.e. the mesoscale features are in the same locations and the Kuroshio frontal path is similar in both models. This is an example of NLOM, which has the resolution required to properly resolve the ocean mesoscale, constraining the lower resolution NCOM to allow an accurate initialization for the NCOM shortterm forecast. Having a more accurate initialization with the mesoscale features in the right location will allow NCOM to provide more accurate boundary conditions to nested higher resolution coastal and relocatable models. It will also help to improve the SST forecasts by improving the mesoscale advection field. Real-time results are available on the NCOM web site at http://www7320.nrlssc.navy.mil/global_ncom.

\section{Summary}

The components of NRL's NLOM/NCOM global system and initial validations of the assimilative models have been described in this report. The system consists of a $1 / 16^{\circ}$ global version of NLOM that has been running in real-time since 18 October 2000 and a $18^{\circ}$ global version of NCOM running in real-time since 26 October 2001. The NLOM component became an operational product at the Naval Oceanographic Office on 27 September 2001. It includes a bulk mixed-layer formulation and assimilation based on OI deviation analysis using the model as a first guess, subsurface statistical inference, and slow data insertion. NCOM has a more sophisticated mixedlayer model and assimilates synthetic temperature and salinity profiles from MODAS based on the NLOM SSH field and the MODAS SST analysis. Both models are forced by FNMOC wind and thermal forcing products and assimilate SST from the MODAS global SST analysis.

The NLOM system has been validated for nowcast and forecast skill compared to independent observations. Comparisons of MODAS synthetic temperature profiles calculated using NLOM SSH and the global MODAS 2-D analysis SSH were performed. The comparisons with independent XBTs showed that the NLOM derived synthetic profiles were overall better than the MODAS derived profiles. Both NLOM and MODAS 2-D derived synthetics were superior to climatology especially where there are significant anomalies, including mesoscale variability.

The NLOM system was tested for its ability to nowcast locations of major ocean fronts and eddies and will be used to improve the quality of the NAVOCEANO frontal analysis products. The position of fronts from the NLOM SSH field showed good agreement with independent NAVOCEANO frontal analyses for the Gulf Stream. The errors in the NAVO-
CEANO analysis are mainly due to IR imagery that is difficult or impossible to interpret because of clouds. The NLOM provides a useful guidance product for the WSC analyst to improve the frontal analysis in areas where interpretation of IR imagery is difficult due to the clouds or during the warmer months when the fronts lose their surface SST signal.

The ability of NLOM to forecast the global SSH field was also tested. NLOM 30-day forecasts were verified against later analyses and results shown for the global domain plus the Kuroshio and Gulf Stream subregions. Results indicated that for the global and Kuroshio domains, NLOM showed skill over persistence and climatology for SSH prediction for at least 30 days and in the Gulf Stream region for $\sim 18$ days. This is consistent with previous NRL research that indicates that $1 / 16^{\circ}$ resolution is adequate for the Kuroshio, but $1 / 32^{\circ}$ resolution is required for more accurate representation of the Gulf Stream.

Initial validations were shown for global NCOM, including SST prediction skill and the ability of NCOM to nowcast the positions of major fronts and eddies. Results indicated that for the $14^{\circ}$ version of global NCOM, that has been running in real-time since August 2000, the model 2-day SST forecast had lower errors than persistence when compared to the analysis valid on the forecast day. The $18^{\circ}$ version of global NCOM is now running in real time assimilating MODAS synthetic temperature and salinity profiles derived from the NLOM SSH nowcast and the MODAS SST analysis. The NCOM SSH nowcast was shown to compare well with the positions of mesoscale features seen in the NLOM SSH nowcast, which has verified skill in nowcasting the position of ocean fronts and eddies.

\section{Acknowledgments}

This work was performed as part of the NRL 6.4 Large-scale Models, the 6.4 Ocean Data Assimilation, and the 6.4 Altimeter Data Fusion Center Support projects, managed by the Space and Naval Warfare Systems Command under program element $0603207 N$. It is also a contribution of the completed 6.2 Basin-Scale Ocean Prediction System project, as part of the Naval Ocean Modeling and Prediction program under program element $0602435 \mathrm{~N}$ at the Office of Naval Research. The $1 / 16^{\circ}$ global ocean model was run on the NAVOCEANO Cray T3E and IBM SP3. The $14^{\circ}$ and $1 / 8^{\circ}$ NCOM global ocean models were run on the IBM SP3 using grants of computer time from the DoD High Performance Computing Modernization Office with much of the NLOM time under an FY98-00 DoD Challenge Project entitled "Global and basin-scale ocean modeling and prediction." The authors would also like to thank Jan Dastugue, Gregg Jacobs, Bruce Lunde, Lee McKinney, Tammy Townsend, and Kirk Whitmer for their support of the real-time systems. This is NRL contribution number NRL/JA/7320/01/0012 and is approved for public release, distribution unlimited. 


\section{References}

Blumberg, A.F. and G.L. Mellor, 1983: Diagnostic and prognostic numerical circulation studies of the South Atlantic Bight. J. Geophys. Res., 88, 4579-4592.

Blumberg, A.F. and G.L. Mellor, 1987: A description of a three-dimensional coastal ocean circulation model. In: Three-Dimensional Coastal Ocean Models. N. Heaps, Ed., American Geophysical Union, New York, N.Y., 208 pp.

Fox, D.N., W.J. Teague, C.N. Barron, M.R. Carnes and C.M. Lee, 2001: The Modular Ocean Data Assimilation System (MODAS). J. Atmos. Oceanic Technol., 19, 240-252.

Harding, J.M., M.C. Carnes, R.H. Preller and R.C. Rhodes, 1999: The Naval Research Laboratory role in Naval ocean prediction. Mar. Technol. Soc. J., 33, 67-79.

Hellerman, S. and M. Rosenstein, 1983: Normal monthly wind stress over the world ocean with error estimates. J. Phys. Oceanogr., 13, 1093-1104.

Hogan, P.J. and H.E. Hurlburt, 2000: Impact of upper ocean-topographical coupling and isopycnal outcropping in Japan/East Sea models with $1 / 8^{\circ}$ to $1 / 64^{\circ}$ resolution. J. Phys. Oceanogr., 30, 2535-2561.

Hurlburt, H.E. and P.J. Hogan, 2000: Impact of $18^{\circ}$ to $1 / 64^{\circ}$ resolution on Gulf Stream model-data comparisons in basin-scale subtropical Atlantic Ocean models. Dyn. Atmos. Ocean., 32, 283-329.

Hurlburt, H.E. and E.J. Metzger, 1998: Bifurcation of the Kuroshio Extension at the Shatsky Rise. J. Geophys. Res., 103, 7549-7566.

Hurlburt, H.E. and J.D. Thompson, 1980: A numerical study of Loop Current intrusions and eddy shedding. J. Phys. Oceanogr., 10, 1611-1651.

Hurlburt, H.E., D.N. Fox, and E.J. Metzger, 1990: Statistical inference of weakly correlated subthermocline fields from satellite altimeter data. J. Geophys. Res., 95, 11,375-11,409.

Hurlburt, H.E., A.J. Wallcraft, W.J. Schmitz Jr., P.J. Hogan, and E.J. Metzger, 1996: Dynamics of the Kuroshio/Oyashio current system using eddy-resolving models of the North Pacific Ocean. J. Geophys. Res., 101, 941-976.

International GODAE Steering Team, 2000: Global Ocean Data Assimilation Experiment Strategic Plan. GODAE Report \#6. Published by the GODAE International Project Office, Bureau of Meteorology, Melbourne, Australia, 26 pp.

Jacobs, G.A., C.N. Barron, M.R. Carnes, D.N. Fox, H.E. Hurlburt, P. Pistek, R.C. Rhodes, W.J. Teague, J.P. Blaha, O.M. Smedstad, R. Crout and K.R. Whitmer, 1999: Navy altimeter data requirements. NRL Formal Report 7320-99-9696. Nav. Res. Lab., Stennis Space Center, Miss., 25 pp.

Jacobs, G.A., H.E. Hurlburt, J.C. Kindle, E.J. Metzger, J.L. Mitchell, W.J. Teague and A.J. Wallcraft, 1994: Decadescale trans-Pacific propagation and warming effects of an El Niño anomaly. Nature, 370, 360-363.

Martin, P.J., 2000: Description of the Navy Coastal Ocean Model Version 1.0. NRL Formal Report 7322-00-9962. Nav. Res. Lab., Stennis Space Center, Miss., 45 pp.

Martin, P.J., G. Peggion and K.J. Yip, 1998: A comparison of several coastal ocean models. NRL Formal Report
7322-97-9692. Nav. Res. Lab., Stennis Space Center, Miss., 96 pp.

Mellor, G.L. and T. Yamada, 1982: Development of a turbulence closure model for geophysical fluid problems. Rev. Geophys. Space Phys., 20, 851-875.

Metzger, E.J. and H.E. Hurlburt, 1996: Coupled dynamics of the South China Sea, the Sulu Sea, and the Pacific Ocean. J. Geophys. Res., 101, 12,331-12,352.

Metzger, E.J. and H.E. Hurlburt, 2001: The importance of high horizontal resolution and accurate coastline geometry in modeling South China Sea inflow. Geophys. Res. Let., 28, 1059-1062.

Moore, D.R. and A.J. Wallcraft, 1998: Formulation of the NRL Layered Ocean Model in spherical coordinates. NRL Contractor Report 7323-96-0005. Nav. Res. Lab., Stennis Space Center, Miss., 24 pp.

Murphy, A.H. and E.S. Epstein, 1989: Skill scores and correlation coefficients in model verification. Mon. Wea. Rev., 117, 572-581.

Shriver, J.F. and H.E. Hurlburt, 1997: The contribution of the global thermohaline circulation to the Pacific to Indian Ocean throughflow via Indonesia. J. Geophys. Res., 102, 5491-5511.

Smedstad, O.M. and D.N. Fox, 1994: Assimilation of altimeter data in a two-layer primitive equation model of the Gulf Stream. J. Phys. Oceanogr., 24, 305-325.

Tilburg, C.E., H.E. Hurlburt, J.J. O'Brien and J.F. Shriver, 2001: The dynamics of the East Australian current system: The Tasman front, the East Auckland current and the East Cape current. J. Phys. Oceanogr., 31, 2917-2943.

Wallcraft, A.J., 1991: The Navy Layered Ocean Model user's guide. NOARL Report 35. Nav. Res. Lab., Stennis Space Center, Miss., 21 pp.

Wallcraft, A.J. and D.R. Moore, 1997: The NRL Layered Ocean Model. Parallel Computing, 23, 2227-2242.

Wallcraft, A.J., A.B. Kara, H.E. Hurlburt, and P.A. Rochford, 2002: The NRL Layered Global Ocean Model (NLOM) with an embedded mixed layer sub-model: Formulations and model simulations. J. Atmos.Oceanic Technol. (submitted). 